\title{
Repercusiones del hecho del consumo en las vicisitudes del Derecho Social* $^{*}$
}

\author{
Manuel M. ${ }^{a}$ Zorrilla Ruiz \\ Catedrático Emérito de la Universidad de Deusto \\ Ex-Presidente del Tribunal Superior de Justicia del País Vasco \\ Presidente de la Asociación de Jueces y Magistrados Jubilados de España
}

\begin{abstract}
Resumen: Las peripecias del hecho del consumo se relacionan con los cambios sucesivos del Derecho Social. El Estado de Bienestar favoreció el hecho del consumo, a causa de las circunstancias peculiares de la era de la prosperidad. La moda de la productividad aceleró el hecho del consumo y la inconsciente cooperación de los trabajadores a la obtención de la plusvalía que los empleadores lograban. La crisis económica - interminable y complicada - impuso soluciones cualitativas para reordenar el Derecho Social, salvaguardar el empleo escaso y mitigar la propensión al hecho del consumo. La globalización ha impulsado el hecho del consumo y sentado las bases del tratamiento neoliberal del Derecho Social, beneficiando al capital en detrimento de los trabajadores dependientes.
\end{abstract}

Palabras clave: adquisiciones cualitativas, disolución del conflicto industrial, globalización, hecho del consumo, relaciones de trabajo.

Abstract: The events of the fact of consumption are related with the succesive changes of the Social Law. The Welfare State favoured the fact of consumption, duty to the circumstances of the age of the prosperity. The fashion of the productivity increased the fact of consumption and the inconscious cooperation given by the workers to the gain in value in profite of the employers. The economic crisis, complex and limitless, imposed qualitative solutions to put in order the Social Law, protect the slight employment and moderate the propension to the fact of consumption. The globalization has impelled the fact of consumption and has put the basis of the neoliberal treatment for the Social Law, in profite of the capital, but being in detriment of the dependent workers.

Key words: qualitative advantages, dissolution of the industrial conflict, globalization, fact of consumption, labour relations.

Sumario: I. Evolución y proyección general del hecho del consumo. - II. Devaluación del hecho del trabajo y exaltación del hecho del consumo. - III. Reacción anticonsumista de orden cualitativo. - IV. Dispersión histórica del hecho del consumo y de las relaciones de trabajo. V. Suerte del hecho del consumo tras la instalación del estado social y

* Ponencia presentada por el autor en el Congreso Internacional sobre Derecho de Consumo, celebrado en la Universidad de Deusto (Bilbao), los días 26 a 28 de junio de 2006. 
democrático de derecho. - VI. Impacto de la productividad industrial en el hecho del consumo. - VII. Correlaciones de la plusvalía y el hecho del consumo. - VIII. Destino del hecho del consumo ante el advenimiento de la crisis económica. - IX. Interconexiones del hecho del consumo, las mudanzas de las relaciones de trabajo y el fenómeno de la economía general. - X. ¿Hacia la privatización neoliberal del régimen jurídico de las relaciones de trabajo? - XI. Espectro consumista de los programas globalizadores. - XII. Función de las relaciones colectivas de trabajo en el hecho del consumo de los bienes y servicios esenciales de la comunidad. - XIII. Reflexión final.

\section{Evocación y proyección general del hecho del consumo}

El hecho del consumo es el resultado de la distribución y puesta en el mercado de libre competencia, y de la obtención de bienes materiales y/o prestaciones de servicios a través de un título jurídicamente válido para integrarlos en el patrimonio de los adquirentes. A las transformaciones físicas de los factores productivos consistentes — por orden de complejidad-en materias primas, bienes de producción, en su acepción más amplia, y bienes de consumo incorporados a partir del ciclo que los origina, siguen su distribución y oferta en circunstancias de lugar y de tiempo que, sin cambios de sustancia o accidente, pretenden extraer un lucro económico de su reparto y enajenación. Beneficio que, tratándose de servicios en sentido estricto, asocia ese lucro a una transformación cualitativa que no muda su identidad originaria.

El hecho del consumo - que inicialmente designa la superación de las formas primarias de la economía de sobrevivencia - termina acampando bajo la dominación que el ejercicio de la libertad de empresa impone en aquellos episodios que abordan las reivindicaciones colectivas -cuando reclaman el cumplimiento de las funciones sociales de dicha libertad- o practican un ecumenismo consumista que, impregnado de intenciones de signo variable, sugiere un cambio sustancial del curso de los acontecimientos.

Tardó algún tiempo en abrirse paso la idea de que incluso las aseveraciones de la filosofía perenne no desautorizaban un marco de laicismo económico en el que había lugar para una perspectiva secular de las operaciones típicas del hecho del consumo. Algo que, atisbado en principio como una exhibición de atrevimiento y avalado después por interpretaciones respetables, terminó confirmándose por vía de deducciones convincentes. Si se cita este ejemplo, no es por su especialidad anecdótica y sí para apuntar la variedad de las conexiones que un lúcido examen del hecho del consumo contribuye a descubrir y/o aclarar.

Las doctrinas jurídico-políticas surgidas al calor de la era de los descubrimientos despertaron la preocupación por un neoconsumismo en que la 
relación de servicios del trabajo dependiente subyacía al grosor de otras consideraciones de base que procedía hacer a la sazón. La tesis calvinista de que el éxito de las operaciones lucrativas respaldaba la bondad moral de los triunfadores económicos y anunciaba su salvación eterna, muestra - con cinismo subliminal e insuperable - los estímulos de una concepción abusiva del consumo y practica una aberrante exaltación de quienes profesionalmente se entregaban a satisfacer sus exigencias. Las reglas colegidas de esta ideología no sólo abarcaban a quienes, mediante la producción, predisponían al consumo, sino también a cuantos soportaban una situación de dependencia de mercado que, a la larga, definiría a la nueva clase - la de los trabajadores por cuenta ajena- como el primero y más sacrificado de los grupos parciales de la futura sociedad pluralista.

\section{Devaluación del hecho del trabajo y exaltación del hecho del consumo}

El designio de convertir la sociedad en un campo sin fronteras para las avideces consumistas — subrayando sus excelencias, naturales o artificiosas, y velando la fealdad de su rostro diabólico — ha pospuesto los escasos valores morales del fenómeno y suscitado reflexiones que, pocas veces, elogian su prevalecimiento $\mathrm{y}$, más frecuentemente, le censuran o enumeran sus tachas. El hecho del consumo ha provocado una subestimación del hecho del trabajo que, como factor productivo, incrementa el valor de los bienes y servicios dados al mercado y brindados a los consumidores por los que aprovechan la plusvalía emanada de sus transformaciones. Se fuerza - hoy más que nunca y menos que en un futuro de cierta temibilidad - la tarea de edificar un universo gobernado por una idea intelectual y moralmente detestable. La de que, ante lo perentorio de enriquecerse mediante las operaciones de consumo subsiguientes a las de producción y puesta en el mercado, los pobres —desheredados e indefinidamente débiles - están llamados a protagonizar unos capítulos históricos en los que pierden siempre las batallas libradas en pro de su liberación. Bien, porque, en los vergonzosos escenarios donde luce y escandaliza su pobreza, poco importa su suerte, si la capacidad de consumir no cuenta y, en su lugar, menudean los auxilios humanitarios que son la coartada de la negativa a liberarlos. Bien, porque ciertos cambios de las relaciones de trabajo merman las exigencias de consumo que aquejan a quienes más necesitan de su satisfacción.

Cuando se invocan o cuestionan la moralidad y la modernidad de la globalización - multiplicadores galopantes de un hecho del consumo que, además de desbordar las previsiones razonables, superan las conjeturas más fantásticas - se endurecen los rasgos del rostro diabólico que caracteriza a su finalidad de alienación. Para que el consumo sobreviva en el universo achicado o tierra plana que funda su fenomenología, se fabrican ciertas reglas de juego. Se sostiene que la utilidad o beneficio industrial que reporta al oferen- 
te de bienes y/o servicios su puesta en el mercado no debe sufrir el castigo de la parte de los costes de producción que, según las pautas del Estado social y democrático de Derecho, convienen a unas condiciones equitativas de trabajo y, en concreto, a la suficiencia remuneratoria de los trabajadores dependientes. La cosmoeminencia de la dignidad de la persona individual deja de ser, para las especulaciones consumistas, un objetivo respetable y se convierte en la más seria de las objeciones implícitas en los valores de una libertad inviolable e inteligentemente comprendida.

De ahí, los propósitos - tenaces y maléficos - de atentar contra esa dignidad por medio de mecanismos reductores. Consiste uno de ellos en aprovechar las condiciones de competencia fomentadas por una globalización que borra la compartimentación de los mercados, estableciendo, entre ellos, un sistema osmótico de interpenetración que elimina las barreras obstructivas de las aproximaciones geográficas. Otro arbitrio vigoriza estas posibilidades, contrariando las acciones sindicales y minando la fuerza de los poderes que las determinan. Remedios que suprimen, ya que no todos, buena parte de los obstáculos surgidos a la edificación de un universo consumista que tiende a crecer indefinidamente.

Según las líneas de fuerza del principio de irreversibilidad, que gratificaba los esfuerzos hechos para hacer irrevocables las adquisiciones sociales más imperecederas y costosas, el hecho del consumo reflejaba los aspectos siguientes. Las conquistas se obtenían sin contraprestaciones de los empleadores, porque era ése el imperativo de un poder sindical que las arrancaba en pago de una deuda histórica de largo recorrido. Los empresarios se entregaban a las tareas de acondicionamiento del mercado para mantener unos niveles de consumo - garantizadores de un beneficio económico estimulante y continuado, no desalentador y disperso - que, de otro modo, quedarían perjudicados por las concesiones de una negociación colectiva en que, al contrario de los temas de la contratación individual, el poder sindical - legislador ejerciente de su especial autonomía - dictaba condiciones que integraban el ordenamiento jurídico extraestatal del Derecho Social.

\section{Reacción anticonsumista de orden cualitativo}

Cuando -intuidas las ilusiones que iban más lejos del mero consumismo - cobraron cuerpo las aspiraciones cualitativas de los trabajadores y se expandieron las doctrinas favorables a su función activa en el gobierno de la empresa, los conflictos se trasladaron, por mor de justificados fundamentos, a los centros de trabajo en que sus divergencias se acusaban de modo más álgido. Había que atacar, en primer término, las técnicas de productividad que, lejos de ser comunes a todos los procesos, mostraban variedades - precisas y sutiles- que sustentaban los alicientes de un hecho del consumo tocado por dificultades adquisitivas de bulto. Era preciso evitar que los obje- 
tivos consumistas se explotasen para robustecer los poderes de organización de los empleadores que —obcecados en multiplicar los productos codiciados por los consumidores - restringían excesivamente, cuando no anulaban, el contenido esencial o núcleo invulnerable de los derechos constitucionales de unos trabajadores que devenían ciudadanos de segunda zona en el lugar de empleo. Era forzoso impedir que la obsesión competitiva - dirigida a exasperar la cautividad consumista - no mudase las obligaciones de medios o de simple actividad, a que se contraían las prestaciones profesionales de los trabajadores, en obligaciones de fines o de resultado, que imponían ritmos intensos y genéricos de actividad. Ritmos por encima de los que - como convenía a la naturaleza de las relaciones individuales de empleo- debían atenerse a la cualidad habitual del trabajo y a la noticia que — con los métodos de verificación a su alcance - tuviese el empleador de la aptitud profesional de cada trabajador y de las restricciones que le aquejasen en su caso.

Las dificultades para competir y facilitar a los consumidores unos ritmos de producción económicamente accesibles provenían del encarecimiento de los factores productivos - las materias energéticas o sus sustitutivos de obtención técnicamente costosa- y aconsejaban soluciones flexibles acompañadas de sacrificios compartidos. De ellas formaba parte la puesta en suspenso de la irreversibilidad de las adquisiciones sociales — abandonando la máxima siempre más, nunca bastante... que había forjado este principio-y la socialización de los beneficios industriales mediante inversiones que asignaban a los instrumentos y medios productivos el ejercicio de una función social. Ésta consistiría en mantener activos los ciclos de producción que, al precio de esfuerzos desusados e imaginativos, debían subsistir en beneficio general del empleo y de la cobertura de un consumo que, de no ser así, quedaría dañado en perjuicio de la tutela de cada interés particular y de las expectativas de los intereses generales.

Antes de producirse la invasión de la fenomenología globalizadora, estas opciones suavizaban las cargas de los empleadores que afectaban — porque les era gratificante y útil - una parte de su patrimonio a operaciones de reestructuración y otros objetivos salvíficos, evitando la evaporación de los mercados en que navegaban los activistas del consumo. La territorialización de los conflictos industriales fijaba los términos de la confrontación y confirmaba las servidumbres geofísicas que perpetuaban la condena a enfrentarse y entenderse, para normalizar, con fortuna variable, los roces del sistema de relaciones industriales.

Los eventos de la globalización equivalen al salto cualitativo de concienciación de los experimentos hechos en el espacio de esas relaciones. Se intenta sobreexcitar un consumo - de cuya intensidad y extensión no se desiste - elevado a distintivo indeleble de una sociedad que tampoco renuncia a erigirse en su protagonista estelar y eminente. Nadie ponía en cuestión, al día de ayer, la supervivencia y el vigor iusnaturalista del principio de irreversibilidad de las adquisiciones sociales que, ante la crueldad de las agresiones 
causantes de su ruina, hoy no enmascara su desmoronamiento y su declive. Puede hablarse de una regla de inexorable defensa del consumo a cargo del factor capital que, si se jacta de algo, es de dar -orquestada por la propaganda - la impresión de que, bajo la apariencia evolutiva de que todo cambia aceleradamente, las cosas tienden rabiosamente a no dejar de seguir siendo ellas mismas, lo que, en clave inmovilista, habían sido hasta entonces para su provecho.

La libertad de establecimiento empresarial —que internacionaliza, las bases físicas de la acción productiva- y la libre circulación de capitales -que, valiéndose de esta circunstancia, invade los ámbitos del consumo existente o inaugura otros nuevos - desmantelan las barreras geográficas que acotaban la estanqueidad del clásico conflicto industrial. Permitían emprender acciones útiles para templar las tensiones exageradas del conflicto y devolverle la tensión propia de su subsistencia y eficacia sociales. Los sindicatos gozaban de una fuerza específica - apta para situarlos, como efectivos poderes de hecho, en el marco de las decisiones relativas a los destinos de la sociedad pluralista- que se difundía al ámbito físico de la soberanía estatal. El Estado - alternando las posturas de control y de apoyocumplía los deberes de moral política que simbolizaba su acogida. Pertenecían a un sistema de fuerzas que, gracias a las operaciones de integración y de conflicto, dictaban — pues tal era la realidad subyacente a la negociación colectiva- condiciones generales que se retransmitían a los contratos individuales de trabajo inscritos en cada unidad negociadora o ámbito funcional. Reglas vinculantes para los empleadores, que, al acatarlas, tenían que prever - con visión profética del cúmulo de riesgos industriales que les abrumaban- la reacción diferida y esperada de los consumidores frente a ofertas cuyos precios incluían el coste económico de aquellas concesiones sociales.

\section{Dispersión histórica del hecho del consumo y de las relaciones de tra- bajo}

Una de las victorias de la globalización ha consistido en disolver el conflicto industrial mediante un distanciamiento geográfico de sus protagonistas que conmueve la firme instalación de los agentes sociales del mundo del trabajo en el área territorial del Estado soberano moderno. Lo peculiar del ejercicio de la libertad sindical colectiva era la dedicación de unos sujetos de base institucional - los sindicatos reconocidos por imperio del Derecho de Gentes y asentados en la geografía del Estado que acataba sus funciones históricas $\mathrm{y}$, con salvedades, no obstaba a sus iniciativas - a consolidar las adquisiciones exigidas por la promoción — cuantitativa, en principio, y cualitativa después - de los intereses de la clase trabajadora. Una tutela que, a causa de la perseverancia de su avance, rompe el primitivo marco del interés profesional y amplifica sus modestos objetivos de origen. Esta tarea com- 
prendía el análisis de los círculos de consumo que se localizaban y calificaban mediante operaciones de diagnóstico. Había que predecir, con márgenes mínimos de error, la magnitud de los beneficios industriales que los empleadores deseaban obtener - previa una referencia estadística veraz respecto al hecho del consumo - y cuya exacta evaluación formaba parte —usando de un concepto muy caro al Derecho común de las obligaciones- de la presuposición o base del negocio en las convenciones colectivas de trabajo. El poder sindical - enseñoreado de sus vicisitudes hasta que el cambio y los signos de los tiempos le desplazaron de sus posiciones dominantes- disponía de las referencias ofrecidas por el vasto espectro consumista para seleccionar las reivindicaciones que, en función de esos datos y otros concomitantes, debía ejercitar.

El Estado de Derecho liberal burgués —que asumió las victorias de la revolución industrial e institucionalizó su caja de sorpresas - aceptaba el hecho del consumo como una realidad social inseparable de la Política Legislativa del liberalismo. A buen seguro que - de no haber figurado, inicial e inequívocamente, en el elenco de los objetivos predilectos de esa ciencia de la legislación - el hecho del consumo no habría tardado en irrumpir en la escena social y en plantear los problemas relativos al espíritu y finalidad de las leyes que eventualmente le hubiesen ignorado, haciéndose pionero de una interpretación evolutiva que adelantaba su estreno técnico-jurídico. El Estado demoliberal concibió, sin hartura de imaginación, el hecho del consumo como una contingencia conexa con la suerte - afortunada o decadente- de los procesos productivos que se legitimaban, ante el Derecho objetivo, por atribuir la titularidad y el ejercicio de los derechos subjetivos constitucionales de propiedad privada y de libertad de transacciones comerciales e industriales. Derechos que, aunque básicos en la realidad sociopolítica de entonces, no disfrutaban de unas acciones de apoyo ajenas a los postulados de la filosofía vetoliberal.

Un examen de los diversos sectores económicos — maduros o incipientes- permitiría divisar los campos en que las exigencias consumistas comulgaban con la simplicidad de la estructura social de que eran parte sus sujetos activos, a cuyos intereses proveía un Derecho de satisfacción de necesidades compartidas de antiguo. Se diferenciaban de aquellos otros en que - atisbándose un Derecho de invención de necesidades rastreadas nebulosamente, coincidentes con las demandas concupiscibles del bienestar individual, precisadas de esclarecimiento y de una sistematización elementalanticipaban la popularidad y el crédito sociales que, como fenómeno multidireccional, el hecho del consumo estaba en vías de adquirir.

El carácter y las perspectivas del hecho del consumo incidían, con sensibilidad variable, en la suerte de las relaciones de trabajo que, a falta de respaldo institucional, gozaban del apoyo de las acciones sindicales - ayunas de la necesaria estrategia y hostiles a los poderes de Derecho ya constituidos- y de las reacciones, ocasionales y modestas, de los sectores de una opinión pública mejor o peor ilustrada sobre la magnitud de sus eventos. 
Los regímenes autoritarios de Occidente imprimieron a la producción y al consumo un sello de exaltación patriótica que, sin merma de su repercusión en las relaciones de trabajo, ocultaba un ajuste político de cuentas. La dación de bienes al mercado - sugerente de cautelosas actitudes ante el hecho del consumo o determinante de su capacidad de excitación- escondía, invocando el hecho productivo, designios temibles para el futuro de la familia humana. La producción — que desencadenaba y alentaba el consumo- se concebía como una unidad nacional al servicio de la patria e influía, por partida doble, en la perversión del régimen de las relaciones de trabajo. A la figura bicípite del empobrecido contrato de trabajo, sucedió una estructura tricípite que se justificaba por el interés nacional del sistema autoritario en servir a la patria con los hechos del consumo activados por la intensificación productiva de sus actividades. Cada relación individual de trabajo, así forzada, no nacía del acuerdo de voluntades entre las partes que aparentemente ejercitaban las libertades contractuales. Procedía de un imperativo superior - semejante a la función de la ley como fuente de las obligaciones y a la contradicción en los términos del concepto de contrato forzoso- que, arrinconando la autonomía de los intervenientes, asociaba ese vínculo al deber de acatar el mensaje irrenunciable de la voluntad del Derecho y el Estado. El empresario - responsable ante el Estado del éxito consumista de la producción y convertido en sujeto de un ejercicio privado de funciones públicas - auxiliaba a un consumo de finalidades tenebrosas, que abarcaba dispositivos y operaciones belicistas en pugna con los rasgos constructivos de la economía. El ciudadano - consciente de su fidelidad a los requerimientos patrióticos del hecho del consumo - se insertaba en el proceso por obra y gracia de su obligación de lealtad para con el Estado. Las interacciones de la autonomía de la voluntad individual no contaban con ninguno de los espacios habitables que exigía su naturaleza jurídica.

No se alteraba menos el régimen de las relaciones colectivas. La confrontación de la lucha de clases confería a las acciones sindicales la defensa de intereses desnudos - que, a veces, se elevaban a la categoría de derecho subjetivos - llamados a incidir en las operaciones del hecho del consumo afectadas por esa protección primaria. Dicho antagonismo fue abolido - aunque subyacía conforme a la indisponible naturaleza de las cosas- desde que la filosofía del sistema autoritario mudó los términos de la correlación. Las pretensiones colectivas de los trabajadores se asociaron artificiosamente a las de los empleadores, con los que formaron una sedicente comunidad de intereses compartidos. Quería evitarse que el hecho del consumo - consecuente con el de una producción selectivamente orientada - sufriera situaciones de degradación que, a causa de las acciones colectivas de los trabajadores, inquietasen la continuidad del engendro jurídico-político que se proyectaba. Cerradas las opciones del sindicalismo de reivindicación y abiertas las del sindicalismo patriótico, los productores, alienados por el ímpetu de la propaganda, se incorporaban a ese novedoso propósito. Su 
adhesión al talante nacional se compensaba con condiciones de trabajo que - amén de responder a la grandeza de las ilusiones asumidas - les trasladaban a un sugestivo mercado de consumo y les facilitaba los medios para adquirir los bienes y/o servicios que en él se les ofrecían.

Había una extensa parcela de producción y consumo, en la que —como variante de la actitud genérica que declaraba abolido el conflicto- se sucedían operaciones políticas de intencionalidad unívoca y gran envergadura. La difusión de esta quimérica construcción comunitaria hizo del empresario - responsable ante el Estado de la cantidad, calidad y continuidad de la producción - el agente eficaz que, dejando de enfrentarse a la clase social enajenada por las promesas revolucionarias de su fulminación, pasó a ser - amén de otras incitaciones que se le trasladaban- el promotor de unos hábitos y necesidades consumistas que, olvidando sus antagonismos, los componentes de la comunidad asimilaron con presteza. La doctrina del espacio económico quiso hacer una síntesis —encaminada a demostrar la verosimilitud del fenómeno e imponer el consabido acto de fe- de las aspiraciones de expansión territorial y de la difusión del hecho del consumo. Todo ello sucedió en provecho exclusivo de los productores nacionales y a costa del bienestar social y económico de los Estados transfronterizos soberanos, que soportaron las devastadoras guerras de agresión encaminadas a consumar un atentado inolvidable contra el Derecho de Gentes de su tiempo.

\section{Suerte del hecho del consumo tras la instalación del estado social y democrático de derecho}

Interesa lo suyo vigilar el curso del hecho del consumo desde que, con discutibles criterios de moralidad, las potencias victoriosas de la 2. ${ }^{a}$ Guerra Mundial redistribuyeron las zonas de influencia en que - para la desventura o el prestigio de sus respectivas elecciones- se adoptaron y pusieron a prueba los modelos económicos que unas y otras habían preferido.

Las parcelas de la cultura occidental pasan a conocer una evolución del hecho del consumo que engrandece los rasgos del Derecho encargado de su regulación. No se oculta el cuerpo de las aportaciones del flamante Derecho Social, proveniente de un iusnaturalismo existencial que, atestado de luces, irrumpe en la vida y la esperanza de los seres humanos. Se advierten, como temas sensibles de conciliación y de progreso, la renuncia sindical a la revolución y la penetración del sindicato en el espacio físico de la soberanía del Estado social y democrático de Derecho, cuyas reglas de juego se ofrece a respetar y con cuyos objetivos sociales está dispuesto a comulgar sinceramente. Emerge una negociación colectiva que, para graduar sus posibilidades y sus fines, parte de la averiguación imprescindible sobre las relaciones entre la prosperidad capitalista y el hecho del consumo. Se entiende preci- 
pitadamente que — gracias a la acción de unos sindicatos más partidarios de gestionar convencionalmente las mejoras sociales que de acudir a los cauces conflictivos de reivindicación - se ha tocado techo en la defensa de los intereses de unos trabajadores que, menospreciando la ocasión puesta a su alcance, malinterpretan la grandeza de la peripecia histórica que les ha correspondido vivir. Se resisten numantinamente - al igual que los sindicatos que, tras contribuir a esa mejora de su condición, hacen alto, algo así como marcando el paso - a reconocer que la senda de la revolución no ha agotado su curso y sigue abierta a un porvenir cualitativo en que se hagan realidad las promesas de compartir el ejercicio de los poderes de organización y dirección de las especialidades productivas.

El capital aprovecha el espejismo de falsa plenitud — surgida al calor de las grandiosas conquistas sindicales - para introducir magnitudes notables en pro del hecho del consumo y difundir la tesis de que, gracias a la influencia de este dato, la sociedad próspera ha puesto fin a la confrontación interclasista e implantado una estructura arreglada a los signos de los tiempos. Véase cómo y hasta dónde lo pretende el cuerpo de doctrina económicosocial forjado con ese motivo.

La disponibilidad de las riquezas naturales — autorizada por el sistema internacionalizado de colonización o cuasicolonización que precedió al ejercicio del derecho de autodeterminación de los pueblos - confiere a los procesos productivos un ingrediente de prosperidad que multiplica los estados de cosas en pro del hecho del consumo. El traslado de las invenciones tecnológicas del curso de la guerra a la economía de la paz induce a la apertura de procesos productivos inéditos y a probar la eficacia de descubrimientos que, con aires de reto, complican los hábitos — simplistas y clásicos- de unos consumidores perplejos ante tales sorpresas. Las experiencias de interrelación y sondeo de mercados, que facilitan los antecedentes bélicos, fomentan la multinacionalidad de las empresas y preconizan el triunfo reservado al hecho del consumo en la era de la globalización. Los recursos de la propaganda - que los regímenes autoritarios aplicaron tozudamente a la política- recalcan la utilidad del momento para aprender a dominar las relaciones económicas y no dilapidar las oportunidades en que el auge y la moderna traza del hecho del consumo se van a concretar.

Estas circunstancias y alguna que otra más discreta explican que el hecho del consumo - equitativamente adscrito, en la parte que le toca, a la causa de las conquistas de la justicia social — no sólo cubra las necesidades debidas a unas carencias antecedentes y notorias. Da también paso al disfrute de bienes cuyo provecho se desconocía o cuyas apetencias - artificiosas, muchas de ellas - derivan del manejo de mecanismos de adoctrinamiento e inducción, que, sin declarar probada la necesidad objeto de satisfacción, la diseñan a su capricho y conveniencia.

La ausencia de sensibilidad moral y de inquietud -individuales y colectivas- sobre muchas de las conquistas cualitativas pendientes de desarro- 
llarse y alcanzar el buen fin, conduce a una transformación de la estructura social, fruto de las motivaciones que el hecho del consumo aviva y de las devociones que suscita. El éxito de las reivindicaciones sociales demuestra que se han liquidado las álgidas contradicciones de la lucha de clases y se han civilizado las confrontaciones exasperadas — esto es, no distendidas ni normalizadas - del conflicto industrial. Los sindicatos de Occidente secundan la hoja de ruta de los Estados sociales y democráticos de Derecho y, a cambio de la adopción de las Políticas Sociales que éstos hacen suyas, desisten de la trasnochada obsesión de exterminarlos por la vía revolucionaria de la utopía marxista. La composición dualista de la sociedad —espejo del enfrentamiento irreductible de las clases sociales y de la inviabilidad de su armisticio- se sustituye por una figura estratificada o superposición de plantas sociales, cuyos pobladores comparten una posición que, al diluir sus diferencias, concentra sus afinidades. Las clases sociales pasan a ser las secciones horizontales de una pirámide que acoge a quienes - con independencia de las fuentes de obtención de sus rentas- gozan de la misma aptitud adquisitiva para consumir. La inclinación plausible a una sana proletarización de la clase burguesa degenera en un frenético aburguesamiento de la clase trabajadora, ávida de cambiar, no sin sonrojo, su derecho de primogenitura social por un plato de lentejas.

Los regímenes autoritarios del Occidente europeo invocaron, a título particular, el entusiasmo patriótico común para declarar — contra la Historia- abolida una lucha de clases que querían sumir en el olvido. La refacción democrática de las relaciones sociales —obra del Estado social y democrático de Derecho - se comprime y reduce a sólo una parte de la totalidadad, novedosa y optimista, que sus descubridores predijeron. La proliferación del entusiasmo consumista desconflictiviza las relaciones de trabajo, porque el hecho del consumo — que intensifica y engrosa el bienestar- supone un acicate más inmediato y acuciante que el hecho de la transformación social cualitativa, hipotecado por su lejano y poco accesible porvenir, por la dureza del sacrificio anejo a sus premisas intelectuales y morales, y por la incertidumbre de su consolidación definitiva. Estas motivaciones - resumidas en el surrealismo del miedo a ganar - acompañan al rumbo economicista de unos sindicatos que no aciertan a resumir y ordenar lo que el ejercicio de las libertades sindicales tiene de acción cooperativa y de reacción contestataria. Entienden que el peso específico de su renuncia a la revolución les dispensa, por el momento, de otras cargas y les permite suspender sus compromisos cualitativos frente a la clase trabajadora, a la que, así las cosas, desamparan y rinden un flaco servicio. La exaltación del hecho del consumo juega - junto a sus excelencias secundarias-el papel, menos elogiable y airoso, de congelar la sensibilidad sindical indispensable para cumplir, sin cortapisas, un programa de justicia cabal del régimen de las relaciones industriales.

Otros fueron la concepción y el destino del hecho del consumo en los países ex-socialistas atrapados en la órbita de sujeción —más bien que de 
influencia- soviética. Las operaciones de la revolución pendiente se dieron por conclusas desde el momento en que, sin consultar sus pareceres, el acuerdo de las potencias vencedoras les sumergió en el caudal de una revolución anterior - ya consumada - que, una vez digeridos, les convirtió en dependencias de almacenamiento y exportación del pensamiento marxista. Lo que no siempre hicieron con absoluta sumisión y buen obedecer. La lucha de clases no se entendió abolida, sino que se dijo superada merced a una planificación irreversible que se preciaba de haber puesto fuera de juego los presupuestos conflictivos de las tradicionales relaciones de trabajo. El hecho del consumo perdió su importancia en las economías de ese signo y padeció una crítica cerril que - pese a las claudicaciones de un marxismo progresivamente anfibológico - fustigaba las adicciones de los ciudadanos - fueran o no trabajadores dependientes - de Occidente, desordenadamente entregados a la fruición de consumir con la vehemencia del transparente objeto de un deseo. La lucha de clases se entendió superada, sin visos de renacimiento, porque, aunque luego las cosas ocurrieron de modo distinto, los diarios sucesos de la economía y la política seguían entendiéndose - machaconamente- como sendos capítulos del fin de la Historia que nunca se produjo.

De ahí, la promesa de una sociedad idílica, purgada de los antagonismos que aquella lucha fomentaba, y sustraída a las actitudes de emulación y envidia que engendraban las desigualdades. Ello derivaría de una previsión metodológica a la que se atribuía la eficacia de un automatismo milagroso, y no - como sostuvieron los regímenes autoritarios de corte fascista- de sus imposiciones dogmáticas. El hecho del consumo era la cobertura - controlada y dosificada por el Estado - de las exigencias de los necesitados - que no tenían que ser forzosamente los más desposeídos o carentes de bienesa expensas del esfuerzo de quienes, sacrificando la deseable conmutatividad, estuvieran en condiciones aptas para satisfacerlos. Gratificar a cada uno conforme a sus necesidades y recabar de cada uno según sus posibilidades, sin fricciones político-sociales, confrontaciones álgidas o ajustes de cuentas. Todo un programa de retorno a la inocencia original y de placidez de las relaciones humanas. La identificación del ciudadano con el trabajador y la eliminación de las relaciones de trabajo por cuenta ajena, redujeron el hecho del consumo a un aspecto más de la reprobación del caduco proyecto revolucionario, castigado - con un fracaso cáustico- por la inercia sancionadora de las cosas y la enseñanza de los tiempos que lo aniquilaron.

\section{Impacto de la productividad industrial en el hecho del consumo}

El hecho del consumo y su repercusión en el régimen de las relaciones de trabajo sufren - tras las reflexiones anteriores - el impacto de la productividad y la adhesión a una moda surgida del endurecimiento de la competencia. Esta agresividad nace, a su vez, de la pérdida del control económico 
sobre las riquezas de los países del Tercer Mundo que han tomado - rabiosamente - la salida en la carrera de sus respectivos procesos de descolonización. La marginación del mercado amenaza a los ciclos productivos y a los empleadores que, inhábiles para calificar y asumir unos retos de magnitud desconcertante, descuidan o no aciertan a diseñar las previsiones tecnológicas que, según lo específico de cada variedad o unidad industrial, corrijan las deficiencias advertidas y contengan su acción competitiva en un círculo del que, en otro caso, se ven inapelablemente expulsados. Es natural e inaplazable que - abaratando el precio de los bienes y/o servicios que hay en el mercado y atrayendo las preferencias de los consumidores conscientes de esta coyuntura - se conserven los beneficios industriales y, como cumple a la satisfacción del contenido esencial de la libertad de iniciativa económica, se aumente sensatamente su cuantía. Cuando, sin elevar el número de unidades de producto, el precio de los bienes y/o servicios se reduce para evitar su acumulación y acelerar el hecho del consumo, los oferentes terminan huyendo del mercado de libre competencia. El estudio de sus perspectivas y posibilidades económicas preconiza un futuro consistente en arrostrar - dejando atras toda esperanza - un endeudamiento galopante y, a la postre, causante de su ruina. Si el precio reducido se multiplica por un número de unidades de producto superior al que se generaba antes de aplicarse las transformaciones tecnológicas, se obtienen utilidades mayores que las derivadas de las operaciones aritméticas hechas conforme a los datos de origen, cuya conservación disuade de la voluntad de competir a cuantos empresarios no sean portadores de un virus de autodestrucción económica. No cabe operar con un número menor de unidades, cuyos precios superan a los que atraen las preferencias de los consumidores, porque es ésta la receta infalible para que el desahucio del mercado sobrevenga más tarde o más temprano.

La reordenación del hecho del consumo - alertada por el señuelo de la productividad - trata de defender, contra viento y marea, la avidez con que, ante la reedificación incompleta de las relaciones sociales, el capital había promovido - gracias a la coyuntura de prosperidad económica y a la acción obcecada de la propaganda - una comunidad de consumidores que, de buenas a primeras, se ve amenazada de desintegración. La solución consiste en que, además de atacar el mal surgido, el talante consumista de los trabajadores se eleve a la segunda potencia y se apliquen — con beneficiosa apariencia- a las relaciones de trabajo algunas de las novedades aportadas por los éxitos de la productividad.

La refacción del hecho del consumo transfigura las relaciones de trabajo, al desvirtuarse la deuda de actividad de los trabajadores dependientes - constitutiva de una obligación de medios que se entiende cumplida con el agotamiento de las conductas de atención y cuidado inherentes a la diligencia exigible - y hacerse de ella una obligación de fines o de resultado. Su ejecución deja de limitarse a desplegar la actividad profesional — remunerada a tiempo- durante la preceptiva jornada, con la solicitud y asiduidad típi- 
cas de aquella diligencia. También incluye la retribución del rendimiento -indispensable para el abaratamiento de los precios y el incremento de la oferta cursada a los consumidores - que se cifra en sumas de dinero cuyo importe depende de la evaluación de la eficiencia que las fórmulas de racionalización productiva asignan a cada puesto o grupo de trabajo. Aparecen los incentivos -cualitativamente diferenciados del salario a tiempo-que ponderan el número de unidades de bienes o la cantidad de los servicios obtenidos al aplicar los módulos racionalizadores. Para facilitar, acudiendo a un giro complaciente, el cumplimiento de la obligación de fines imbricada en el tejido de las relaciones de trabajo, hay que sobrepasar los límites de la diligencia naturalmente impuesta por la obligación de medios del trabajador. Este se expone a ritmos de actividad inmisericordes que, ante el arrebato lucrativo de la competencia, rebasan las dosis de atención y cuidado que, hasta entonces, definían pacíficamente la verdadera naturaleza jurídica del deber profesional de trabajar.

Las apetencias de bienestar material y las adicciones consumistas que engendran las técnicas de racionalización productiva — controladas a medias por la entrada y la contestación del sindicato en el lugar de empleo- excitan la cautividad de los trabajadores respecto al hecho del consumo. Le satisfacen dominados por unos mecanismos que les enajenan y confiscan la dignidad necesaria para expresar, sin cortapisas, la plenitud de la personalidad explícita en el hecho del trabajo creador. Amén de los conflictos interpersonales que provocan, los usos innovados hacen de los trabajadores cautivos unos conspicuos cómplices de la explotación que experimentan y unos pacientes ignorantes de la plusvalía que se les arranca. Tal es el saldo de los episodios de sumisa capitulación ante unas pautas racionalizadoras que, a tenor de la productividad inventada para competir, dictan este modo de participar en los ciclos de producción, aunque también obligan a otro estilo - más eficaz, sin duda — de acción sindical y mudan de lugar los horizontes de localización y desencadenamiento del conflicto. La teoría de la lucha continua delimita los campos y apunta las estrategias defensivas que procede emplear para contener esos avances y mantener a los trabajadores informados sobre el peligro de su disvalor.

La endemia consumista - irreversible como tal- ya no reside tanto en lo alarmante del fenómeno que trasluce, cuanto en las consecuencias catequéticas de su invasión en la metodología del trabajo. Constituye el sucedáneo o la contrafigura esperpéntica de los ideales cualitativos - a saber, la tutela de los derechos constitucionales de los trabajadores en el lugar de empleo y de su advenimiento a la dirección y gobierno de la empresa- que seguían siendo los ideales retadores en el universo de las relaciones de trabajo, aunque sus pobladores — secuestrados por la impenitente adicción al consumo - habían errado de raíz al no elegir la dirección acertada. Sin sensibilizarse a estos inconvenientes de grueso calibre, el Estado social y democrático de Derecho puso todas sus complacencias en la visión — tan ingenua 
como históricamente alicorta- de un futuro socialmente justo y perdurable por tiempo indefinido. Le faltaron intuición y arrestos para adoptar una Política Social transformadora que, ante una crisis intranquilizadora y perceptible, diera luz verde a los avances cualitativos y rehabilitase la dignidad hurtada al hecho del consumo. El duelo entre la productividad y la participación estaba entonces a punto de empezar.

No sin tropiezos y demoras, se operaba un cambio en la estructura y dimensiones del sindicalismo tradicional, que — para defender los intereses colectivos de los trabajadores frente a la enajenación consumista y la perversión del hecho del consumo exaltada por la productividad-soportaban algunas correcciones. Una de ellas, rehacía la morfología sindical e ideaba las variantes aptas para frecuentar, fuera ya de los grandes espacios sociales, las guerras de guerrillas que iban a librarse en los campos de batalla del lugar de empleo. Otra inventó la teoría de la lucha sindical continua y del conflicto permanente, que decía no a las contraprestaciones de la tregua productivista, defendía la ininterrupción y la agresividad de las contiendas sindicales, y desautorizaba los compromisos contraídos en nombre del deber de paz.

\section{Correlaciones de la plusvalía y el hecho del consumo}

Todas estas reacciones obedecen al agravio de la plusvalía que dimana de aplicar las reglas y agotar los experimentos de la racionalización productiva. La conexión del hecho del consumo con la conmutatividad necesaria y deseable en las relaciones individuales de trabajo, exhuma una plusvalía patente en las innovaciones que aparejan los objetivos de la productividad y el ejercicio de un derecho de resistencia sindical frente a sus agresiones. La plusvalía denota la ruptura — más o menos velada - de la equivalencia objetiva de las prestaciones de los contratos de trabajo en los procesos productivos que preceden a la dación de bienes y al hecho del consumo de los mercados de libre competencia. Se sostenía que, en el contexto del Estado demoliberal, la plusvalía - tal y como enseñaba su candidez diabólica - compensaba los riesgos queridos y corridos por los empresarios que - con ánimo de lucro y asumiendo las probabilidades, ordinarias o extraordinarias, de no lograr las ventajas patrimoniales anejas a sus iniciativas - retenían anticipadamente, como parte de los beneficios previstos, algo que, en justicia material y en equidad, les era indebido. Confiscaban lo que, desde esa perspectiva, suponía la adhesión de la personalidad y la creatividad del trabajador a los actos transformadores en que participaba. Imperaba la idea de que aquél —cautivo de las técnicas de productividad y privado de transmitir a los bienes y/o servicios consumibles su impronta personal-se relacionaba con el resultado final de su trabajo como con un objeto - extraño e irreconocible-que, desencantándole, malograba su perfección individual. 
La concepción rudimentaria, pero certeramente definida, de la plusvalía subrayaba la confiscación o requisa - obra de los propietarios de los instrumentos y medios de producción- de la energía, manual por lo común, y, menos frecuentemente, intelectual que los trabajadores transmitían a los demás factores del ciclo productivo. La situación de dependencia exigía acomodar su esfuerzo y sus capacidades a las directrices de organización que, para consumar los cambios necesarios, adoptaban los titulares de la libertad de empresa. Estas transformaciones provocaban la conversión del producto en un cuerpo cierto o determinaban el aderezo del servicio, seguidos de la distribución en que consistían la dación al mercado y el ofrecimiento a los sujetos activos del hecho del consumo. De ahí, los incrementos o dosis de valor añadido al coste de las materias primas o, más exactamente, de los bienes de producción a los que se aplicaban la fuerza de trabajo y los avances de la tecnología. De este incremento - incluido en el coste del bien de consumo - se adueñaba el capital, remunerando a los trabajadores dependientes con salarios de menor cuantía que la que, según los criterios de conmutatividad o equivalencia objetiva de las prestaciones, requerían la cantidad y calidad de su cooperación.

Aunque la plusvalía se alimenta de aportaciones tecnológicas que agrandan su potencial maléfico, no ha prevalecido - quién sabe por qué motivaciones o acicates - una crítica demasiado escandalizada de los males explícitos en sus evidencias. La desnaturalización del hecho del consumo - que encarna y origina - la convierte en algo que, ofuscándoles, cautiva a los perceptores de rentas de trabajo, más como fuente de un bienestar por el que acaban pagando un alto precio, que como ayuda al crecimiento de la dignidad personal que se ve reflejada en el espejo de la obra bien hecha, deleitosamente cultivada y amorosamente concluida.

\section{Destino del hecho del consumo ante el advenimiento de la crisis económica}

La crisis económica forzó el hallazgo o invención - fruto de una especie de fuerza mayor universal - de un Derecho Social caracterizado por la quiebra del principio de irregresividad de las adquisiciones sociales y por la asignación de nuevas funciones sociales a la libertad de iniciativa empresarial en los mercados de libre concurrencia. No abordó los problemas de la conexión del hecho del consumo con las reivindicaciones defensivas del - en su acepción más laxa y divulgada por la jerga de los sindicatos-acervo de derechos adquiridos de los trabajadores, cuyas excursiones consumistas - fogosamente espoleadas por la concupiscencia de una sociedad próspera - no se apagaron, de súbito, con el advenimiento de la crisis, sino que pasaron de un estado de normalidad, sin prevenciones, a un desazonado estado de alarma. 
La verdad histórica daba cuenta y razón de una monetización de la negociación colectiva, cuya rotulación ilustraba, de paso, sobre las depresiones semánticas de algunas zonas del lenguaje del Derecho de las relaciones de trabajo. Habían corrido parejas las conquistas debidas al asentamiento del Estado social y democrático de Derecho - como la excelencia de la negociación colectiva, en vez de la endemoniada conflictividad que la precedía- - y a la renuncia de los sindicatos a la revolución en los espacios económicos de la cultura occidental y de la ambientación social anglosajona. Los trabajadores compartían la condición de destinatarios del nuevo Derecho Social y la de demandantes de bienes y servicios que - ahora ligados a la promoción del bienestar - se les habían rehusado, de raíz, en su anterior estado de indigencia. Al revalerse de las normas que les rescatan de ese empobrecimiento, emplazan en un plano cuantitativo - conexo con las evidencias del hecho del consumo - el óptimo de las mejoras deseables y, dentro de ése, gobiernan la parcela de las reclamaciones económicas que fundan sus designios de prosperidad. Hasta que la explosión de la crisis plantea un dilema irreductible, la negociación colectiva - monetizada en demasía - convive con los avances cualitativos que, a impulso de los clamores sindicales de la participación frente a la insistencia de la racionalización productiva, sostienen los objetivos sociales de liberación. Unas expectativas que la virulencia y la contumacia de la crisis - como suceso inesperado, como compañera de viaje de las andanzas económicas, como hecho históricamente irrefutable y como realidad devastadora del Derecho Social - fueron, al cabo de un tiempo transcurrido demasiado pronto, devaluando y dejando fuera de combate.

\section{Interconexiones del hecho del consumo, las mudanzas de las relacio- nes de trabajo y el fenómeno de la economía general}

La velocidad adquisitiva de la penetración de los trabajadores en el orbe consumista desencadena unos efectos que completan la tutela de intereses desprotegidos hasta entonces, que se suman a la causa de los demás consumidores y que — ante la ampliación de esa comunidad incidental — resuenan en el panorama de la economía general.

Los organismos internacionales competentes en materia económica recuerdan - con la vehemencia del que, so pena de condenación eterna, reitera las máximas de un dogma de fe-que el poder adquisitivo de las rentas de trabajo, comprensivas de las retribuciones salariales y los emolumentos de los empleados públicos, no se mejora incrementando intempestivamente las sumas de dinero en que consisten. Ahí residen el error capital de la monetización de la negociación colectiva y el falso prestigio de los postulados sindicales que han circulado de su mano. La espiral de inflación - a que esas alzas dan lugar- destruye las ventajas que sus perceptores reivindican en 
clave social y recorta el poder adquisitivo de las unidades monetarias que ingresan. Se ha de prever - austera y escrupulosamente - un crecimiento de dimensiones racionales que, situando en su justo medio la subjetividad de las reivindicaciones consumistas y la objetividad del hecho del consumo, evite que la capacidad de adquisición dependa de una voluptuosidad antisocial, cuando lo suyo es erigirse en un elemento selectivo para cada economía individual o familiar. De ahí, la siguiente consideración.

Los sindicatos - cuyos estados mayores no han ignorado el rigor técnico de esta recomendación machacona - la impugnan sosteniendo que, lejos de enunciar una pauta estabilizadora y conveniente para la buena marcha de la economía general, responde a la terca obsesión capitalista de asegurar la continuidad del beneficio, mediante la plusvalía que se arranca y que, a toda costa, quiere perpetuarse. Las evidencias de la crisis económica obligaron a aceptar la verdad y la necesidad de aplicar una regla que los sindicatos no atacaban a causa de su heterodoxia, sino del ademán testimonial que, para disentir de esas propuestas, les imponían su miedo al descrédito y la carga de sus compromisos históricos. Vigente el Derecho Social de la prosperidad, servía de poco apelar al principio restrictivo de la moderación salarial en pro de la economía general. Las victorias sindicales — que combatían ese dogma con su voluntarismo de poderes de hecho y no con la sensatez de una negociación reflexiva - siguieron sosteniendo la tesis de la iliquidez y duración indefinida de la deuda histórica que constituía, desde sus orígenes, una de las reivindicaciones del Estado de Bienestar. De ahí, la protección — tenaz y emocional- del interés consumista de los trabajadores, que, salvo contadas excepciones, convivía con los consejos de prudencialismo económico impartidos para paliar sus insolencias e impedir, a la luz de una flexibilidad fiel a sí misma y no atestada de malos ejemplos, la degradación de las relaciones de trabajo.

El hecho de la globalización - abierto a múltiples insinuaciones y vertientes - ha encontrado la clave de sus desafíos en el fenómeno del achicamiento del mundo. Su concepto -indeterminado en lo jurídico, lo social, lo económico y aun en las zonas del hecho religioso- despierta, en lo especulativo, criterios apasionados y dispares. Da lugar, en lo que toca a las acciones, a iniciativas y experiencias que, fascinadas por el asombro y la curiosidad, reaniman, sin cesar, las tentaciones de revisar el discurso - cuyos interrogantes se debaten - sobre el fenómeno proteico que la globalización ha resultado ser y sigue siendo.

\section{X. ¿Hacia la privatización neoliberal del régimen jurídico de las relacio- nes de trabajo?}

Vistas las colisiones y ambigüedades de diagnóstico que originan las divergencias en torno a su etiología general, sus especies, sus disparida- 
des y las apuestas sobre su subsistencia, se han mezclado — sin sistema y sin pausa - las cuestiones relativas a la naturaleza y el rumbo de la crisis económica, a la suerte asignada al hecho del consumo por cuantos lo anhelan y promueven, y al aprovechamiento de ambas circunstancias - subjetiva la una y objetiva la otra- para advenir a unas conclusiones de síntesis.

En vez de un uso provechoso y sujeto a efectivos controles, la opción acogida bajo el rótulo de flexibilidad degeneró en el ejercicio abusivo de las funciones sociales que se le atribuían y se esperaban de su puesta en escena. No palió los excesos del hecho del consumo y conjugó estos propósitos -que, pese a sus apariencias antagónicas, servían a las motivaciones de su causa - con un fin de fiesta desolador y pesimista, semejante al fin de la Historia que la dogmática marxista predijo como el signo fatal de un futuro inmovilizado y sin retorno. Así empieza la devastación o voladura controla$d a$ de unas relaciones de trabajo que — pese a su adelgazamiento y menoscabo- conviven, descabezados sus protagonistas, con la cultura del hecho del consumo auspiciado por la obnubilación del capital. Soslayando, no sin dificultades, las cargas de la proximidad geográfica y las confrontaciones sindicales, el capital quiere librarse del agobio causado por las fricciones de un conflicto que, sin visos de recuperación, tiende a disolverse. ¿Cómo es el vacío que entonces se vislumbra?

La incoación de la crisis económica repercutiría en todos los aspectos de las relaciones individuales y colectivas de trabajo, comenzando por la desmonetización de las ventajas que potenciaban el consumo y que, sumadas a otras adquisiciones sindicales, secundaban la línea trazada por el principio de irregresividad de las adquisiciones sociales. La monetización —que, en la era de la prosperidad, abrió un período rotundamente amnésico para proveer a otras necesidades que se le pospusieron - mantuvo la predilección de los trabajadores por el hecho del consumo en un plano tan eminente como irrenunciable, aunque la conciencia sindical — deudora de tantas obligaciones históricas - no se lograba desprender de unas pretensiones cualitativas en pro de las que era inexcusable continuar luchando. La imagen del hecho del consumo en el marco del Derecho Social, cambió a causa de las tentativas de sortear los escollos de la crisis y evitar la dislocación del viejo mundo - tan ajetreadamente poblado y construido — de las relaciones individuales y colectivas de trabajo.

La respuesta a las conveniencias o demandas de los consumidores de bienes y servicios requería conservar un poder adquisitivo mermado por el grosor de las circunstancias convergentes en la emergencia de la crisis económica. La perspectiva de estar condenados a entenderse —coaceptada por los sindicatos y los empresarios ante el dilema de un menoscabo incorregible de las actividades productivas o el recurso a quién sabe qué arbitrios salvíficos - promueve una pedagogía reductora. Se intenta retirar al hecho del consumo el carácter de aspiración obsesiva y primordial, para que, tras este 
sacrificio, sus rebajas se compensen con ventajas cualitativas y se resarzan los perjuicios colectivos que ha irrogado el nuevo estado de cosas. La renuncia sindical a la revolución exigía que las comunidades modernas - sitas en los círculos de la economía de mercado- adoptasen un modelo de relaciones de trabajo acorde con las señales de prosperidad que alumbraban el nacimiento del Derecho objetivo innovado por el Estado social y democrático de Derecho. La propulsión optimista del hecho del consumo era el detonante del cambio estructural de la sociedad y el freno al flujo de unos propósitos cualitativos que, a pesar de sus evocaciones platónicas, se demoraban con pésima conciencia. Ocurrida la crisis económica, que arruina los ingredientes prósperos de la anterior etapa, el Estado social y democrático de Derecho capitula y asiente a salidas que, entre otras, incluyen una de máximo calado, a saber, la renuncia sindical al principio de irregresividad que hasta entonces se estimaba intangible. Esta abdicación - aneja a la entronización de la flexibilidad laboral - significa que la tutela de los intereses de los trabajadores no va a depender - preponderante y afanosamente- de las ventajas dinerarias que multiplican las experiencias del hecho del consumo e invitan a gustar de sus modalidades veleidosas. Ante la utilidad y la necesidad urgente de ciertos elementos no consumistas de satisfacción, se acometen esfuerzos didácticos para difundir su conocimiento y promover su arraigo.

Conviene realzar los aspectos que — como ejemplo de adoctrinamiento moral, social y económico_ - importan estas novedades. Se alega, en primer término, la relatividad del derecho a un crecimiento sistemático - frecuentemente inmoderado- de las ventajas y utilidades constitutivas del hecho del consumo. En segundo lugar, una parte de los beneficios empresariales - destinados a cumplir una función social — se aplican a las operaciones de reconversión industrial — cuya especificación no es del caso- que, velando por la continuidad y el regular funcionamiento de los procesos productivos, conservan, aunque desmejoradas, las oportunidades de empleo y no destruyen, aunque sí desangelan, la devoción de los asalariados para con el hecho del consumo. Por fin, las utilidades del hecho del consumo de los trabajadores - mermado por las causas críticas que lo determinan- se complementan con el beneficio de las normas colectivas que, gracias al dinamismo de la autonomía sindical, satisfacen intereses cubiertos por una tutela actualizada y vigorosa. Los acuerdos sobre una política de rentas calman la intransigencia del frenesí monetizante que aquejaba a los sindicatos intervenientes en la negociación. Otro tanto sucede con el tratamiento de la deuda de seguridad en el trabajo, comprensiva de los deberes de atención y cuidado que - conforme a la concepción normativa de la culpabilidad — individualizan la diligencia necesaria para preservar el contenido esencial o núcleo invulnerable de los derechos a la integridad física y a la protección de la salud. Cabe citar, en fin, la constitución de las representaciones colectivas en los lugares de empleo —donde, renovándose para evitar la alternativa de morir, la 
estrategia sindical ha enclavado la explosión y la remisión de los conflictos- y la fijación de las garantías que, para ejercer con inmediación sus funciones, se adjudican a los representantes sindicales.

Como no puede menos de ocurrir, las relaciones de trabajo reservan al hecho del consumo las ventajas de un espacio habitable dotado de oportunidades económicas o monetizantes, pero también se abren a un marco amplificado, en el que el economicismo de la actividad profesional pierde algo de su peso específico. Se integra y armoniza inteligentemente con adquisiciones - no menos sustanciales- que, poniendo el hecho del consumo en su lugar, exhuman aspectos notables que, haciendo de la necesidad virtud, reciben el auxilio de las nuevas especies de tutela.

Este programa - conciliador y reflexivo- se vio frustrado, demasiado pronto, por la dificultad de gestionar - coadministrándolas con prudencia y conocimiento de causa - las manifestaciones de la noción de flexibilidad individual o colectiva, cuyos experimentos invitaban a compartir, honesta y atinadamente, responsabilidades de hondura. La innovación no funcionó con la severidad cartesiana que, según el optimismo de sus definidores, profetizaba el éxito del proyectado ensayo. Han abundado las aplicaciones abusivas de la idea de flexibilidad y han escaseado las oportunidades de localizar y corregir, eficaz y ejemplarmente, los numerosos excesos perpetrados al amparo de su elasticidad términológica.

Los sindicatos - apresados por la tela de araña que, restándoles movilidad, congelaba sus iniciativas- descubrieron y denunciaron tardíamente la ausencia de juego limpio — en el que su candidez había confiado- sobre el tratamiento de la crisis económica. Combatieron, sin habilidad y sin fortuna, la imposición de soluciones que, para paliar esos efectos negativos, desgastaban —más allá de lo razonable y equitativamente lícito- los derechos individuales y colectivos de los trabajadores. En el embrollo de luces y de sombras que cegaban el paso a una claridad cegadora y decisiva, el tiempo transcurrió en daño de cuantos - a medida que las inagotables e incontrolables ocurrencias del capital deformaban, hasta la extenuación, el concepto jurídico indeterminado de flexibilidad - se encontraron cada vez más inermes para arrostrar sus desafíos y corregir sus yerros.

Se afianzó así — ganando la partida - el estado de cosas influyente en la privatización neoliberal del Derecho de las relaciones de trabajo. Se simplificaron la fenomenología y el peso específico que el hecho del consumo había conquistado en una parcela social solicitada por tendencias que animaban lo racional y lo concupiscible de sus expresiones. Dirigida la una a conservar los hábitos del hecho del consumo, que se empequeñecían, y orientada la otra a salvar, cuando menos, la mala conciencia del olvido que, en perjuicio de ciertas asignaturas pendientes, estaba a punto de desvanecerse. 


\section{Espectro consumista de los programas globalizadores}

Otros son el mensaje del renacimiento consumista, patente en cuantos episodios avisan de la continuidad y el pluralismo de la globalización, y las derivaciones imprevistas que - según los accidentes de las personas, del tiempo y del lugar- surgen de modo asistemático, pero visible y penetrante. Pueden ser proporcionadas o asimétricas, confusas o intelectualizadas, las contingencias que - revelando las invasiones torrenciales del hecho del consumo - se divisan desde las atalayas globalizadoras. El embeleso del hecho del consumo no puede minimizarse, frente a su indudable e indeleble magnetismo, y exige reconstituir — con una imaginación asediada por los temores de fugacidad o frágil acogida - los alicientes de su fisonomía y el rendimiento de los modelos adoptados. Ello requiere disipar los reparos técnicos y sociológicos -que se le oponen en dosis muy copiosas- y otros, de varia etiología, que, so pretexto de enderezar los rumbos del hecho del consumo, circulan sin consistencia lógica ni poder persuasivo. Aun admitiendo que el hecho del consumo es una constante de la vida actual de relación, no remite el afán de denunciar la concupiscencia económica de cuantos - para lograr la utilidad óptima de sus operaciones-exprimen sus réditos con ardor usurario.

También hay que escrutar - dedicándoles un minucioso examen- ciertas operaciones globalizadoras de que las normas de orden público -imperativas y/o prohibitivas - deben ocuparse, atendiendo a su metodología y sus condiciones de efectividad. La difusión y popularidad de esas opciones se sujetan jurídicamente, pese a quien pese, a los controles que, no sin engorro, compete aún ejercer al antes poderoso y omniprovidente Estado social y democrático de Derecho.

La debilitación sindical, genéricamente entendida, forma parte del programa globalizador. Una estrategia productiva que, obnubilada por la protección de su interés, desprecia las restricciones emanadas del sector social del ordenamiento jurídico o las elude zafiamente, exige - algo así como regresando a la época de la colonia - supeditar, colocándole bajo la espesura de la bota opresora, el poder sindical al poder empresarial. Una audacia notable — que se ensaya de entrada — es disponer, como fórmula de organización saludable, el alejamiento físico que - según el adagio que reza dos no se enfrentan, si uno no quiere la confrontación... - liquide los antagonismos, verificables y cercanos, de dos poderes descomunicados que se sustraen a las tensiones de su proximidad conflictiva. Los empresarios frecuentan la variante de reconversión industrial derivada de la libertad de establecimiento, dispersando - gradualmente o de súbito- los lugares de empleo y seleccionando, si preexisten, o eligiendo, si son de nueva planta, ámbitos territoriales más cómodos para el asentamiento de los procesos productivos y la apertura de los mercados de trabajo. He ahí los espacios en que, a causa de sus diversidades, los oferentes de empleo mediatizan absolutamente las demandas de trabajo, y donde las acciones y reacciones sindicales no se 
intentaron nunca o - huérfanas de popularidad y de arraigo- malviven una desgraciada existencia.

Es éste el diagnóstico veraz, no disfrazado ni encubierto, de la situación que caracteriza a una de las experiencias globalizadoras más generalizadas y frecuentes. Se atisba una disipación o predisolución del conflicto industrial — su certificado de defunción se está expidiendo- que facilita las condiciones óptimas para que, aliviados de su gravosa conflictividad, los hechos productivos garanticen márgenes de beneficio cuyas cifras - calculadas al céntimo, tras la exoneración de aquellas cargas - los hacen compatibles con la presentación de un abanico nuevo de ofertas seductoras para el consumidor.

Las comunidades industriales de origen - en que, por tradición e inevitabilidad histórica, el antagonismo clasista había ganado carta de naturaleza- sufren la evasión migratoria de los capitales que, al restringir las ofertas de empleo y perjudicar la creación de riqueza susceptible de adquisición en ese medio, coloca a las demandas de trabajo en un estado de indigencia que empeora la estrella del hecho del consumo. Se esfuma la base de las contradicciones que, inherentes a la dureza del conflicto, constituían la herramienta indispensable para dignificar las condiciones de trabajo y conseguir ventajas que - aunque taradas por las terapias desmonetizantes de la crisis económica- favorecían el hecho del consumo.

Dos aspectos de la reestructuración contribuyen a que el crecimiento de los beneficios industriales coexista con condiciones propicias a la extensión del hecho del consumo. Es uno la sustitución de mano de obra por tecnología que aminora o suprime los ingredientes indeseables de conflictividad. El otro consiste en la desconcentración productiva que no coloca en el mercado el definitivo bien de producción - resultante de un proceso unitario, indivisible y concentrado- y se vale de formas de interposición contractual entre los empresarios que aportan los elementos confluentes en los bienes íntegros o cuerpos ciertos ofrecidos a los consumidores. No faltan ofertas peculiares que, ante las ventajas económicas de estos procesos de fraccionamiento o dispersión, multiplican los alicientes del hecho del consumo e invitan a desarrollar sus experiencias.

Los hábitos migratorios de los empleadores prosperan a medida que se adueñan de espacios geográficos donde las libertades sindicales fueron siempre algo ignoto y de ejercicio impredecible. Han mediado, unas veces, prejuicios históricos y circunstancias culturales que ni de lejos reparaban en ellas, situándolas al margen de cualquier previsión sobre las actividades productivas. Se ha incoado, en otras ocasiones, un entrenamiento - harto tímido- que poco o nada ha conseguido sin el apoyo de instancias extrasindicales que rivalizan con el poder político y añaden un desaconsejable plus de riesgo social. Los empresarios - aprovechando la oportunidad en pro de la libertad de establecimiento y de la irrestricta circulación de capitalesdominan el hecho del consumo, contemplan sus episodios de aceptación social y sopesan las utilidades que reporta para graduar su magnitud. 
La hegemonía del mercado y el dictado de las condiciones de consumo en los países de origen - donde impera una libertad económica consolidada - se consiguen a costa del desgaste de los poderes sindicales. La fijación de las condiciones básicas de las relaciones de trabajo se sustraen a las estipulaciones de la negociación colectiva y se transfieren al campo de la contratación individual, en que el poder contractual del empleador inutiliza el cuanto de tutela que unos sindicatos erosionados e inseguros no garantizan ni procuran. Abundan los supuestos de conflicto impropio entre trabajadores que, con explicable desazón, ignoran las condiciones de reclutamiento de sus pares, o, con justificada frustración, saben de las ventajas que, a título personal, han obtenido mediante una contratación descolectivizada en el plano de los intereses que abarca y aborda. Los intereses de categoría se difuminan y suplantan por la pulverización de intereses que, según la imagen hobbesiana del instinto de conservación, demuestra que cada trabajador se convierte en un lobo para quienes le son afines en el ejercicio de la actividad profesional que comparten.

Adiós, pues, a las protestas y aclamaciones de solidaridad. El proceso de estimación de la influencia de los salarios en los costes de producción racionaliza la distribución de los bienes y/o servicios dables al mercado, mide los beneficiosos estímulos de su ingreso en él y marca unas pautas del hecho del consumo que, al hacer apetecible la demanda, aceleran también su absorción.

Las acciones sindicales se ciñen a cometidos de gestión y otros de discreta entidad. El nuevo rumbo de los acontecimientos frena la intensidad de la fuerza social que, aun en trance de crisis, caracterizaba a la negociación colectiva - principal fuente del ordenamiento extraestatal - y establecía condiciones, colectivas también, que - como fuentes integradoras o completivas- se propagaban a las relaciones individuales de trabajo en el ámbito funcional asignado. Los empleadores daban los pasos precisos para que, salvados esos inconvenientes, el hecho del consumo, lejos de degradarse, se contuviese en unos niveles compensatorios y aceptables. Lo negativo de la situación se acentúa con el demérito sindical que, arrastrado por su economicismo insaciable, el capital ojea de continuo, para acabar con el estorbo de las viejas garantías - desterradas del nuevo mundo que se globaliza- y escribir, cuanto antes, la página obituaria del Derecho Social. A cambio del refuerzo y el estímulo del hecho del consumo, arden - en la pira funeraria de las reivindicaciones sociales- las más caras de las adquisiciones que la crisis económica empezó aligerando - decíase que temporal y moderadamente- y que la furia de la mundialización se apresta hoy a fulminar sin tregua ni misericordia.

La obsesión del capital era multiplicar el consumo - usando, entre otras muchas, de estas vías - y la de los consumidores en activo, olvidar, sin distinción de estratos sociales, unos imperativos de solidaridad que, pese a todo, renacen y se reconocen allí donde — con insistencia prodigiosa— sur- 
gen consignas dotadas de una sana capacidad de renacimiento y puesta al día. Las más abnegadas y admirables enseñan a reemplazar las avideces consumistas por la devoción que reclaman las perspectivas de un interés general fundado en los retos de la coexistencia, en el sentido idílico de la colaboración y en los alicientes de la participación. Ni más ni menos que la sustitución del bien común aristotélico-tomista por su defensa en clave de modernidad y moralidad seculares.

\section{Función de las relaciones colectivas de trabajo en el hecho del con- sumo de los bienes y servicios esenciales de la comunidad}

Los conocidos con el nombre de servicios esenciales de la comunidad constituyen bienes y/o servicios cuya susceptibilidad de disfrute confiere un carácter especial al hecho del consumo que implica su naturaleza y sus funciones. Satisfacen las necesidades que, de individuales y simplistas, pasan a compartirse por los integrantes de una colectividad o mera coincidencia de personas físicas en un espacio geográfico concreto. Están ahí por circunstancias que, aunque extrañas a la voluntad de coincidencia, crean un sentimiento de comunidad y un proyecto de constituirla en condiciones de solidaridad bastantes para avalar la ilusión depositada puestas en un modo digno y justo de sobrevivir. El imperativo de no disociarse — porque cunde la convicción de que el espíritu de solidaridad o el instinto de conservación han vencido al arrinconamiento de una vida insular - obliga a aceptar la necesidad del hecho del consumo y a ordenar esa práctica.

$\mathrm{El}$ hecho del consumo de bienes y servicios esenciales se justifica porque, a falta de ellos, la comunidad — recién erigida — se disloca y adviene a un estado regresivo de disolución. Retoma el carácter inorgánico de colectividad, como si nunca hubiese existido la conversión emanada del pacto social que le dio vida en momentos difíciles de enclavar históricamente. De ahí, la consolidación de un interés general — del que es parte la continuidad del ciclo de satisfacción de los bienes y servicios esenciales- que merece consideración.

Las relaciones colectivas de trabajo pueden, ante el control costoso de su normalidad, superar el nivel habitual de sus tensiones —inherente a la estructura clásica de los conflictos industriales- y afluir a estados de enrarecimiento que interrumpen el funcionamiento regular de los servicios esenciales. El perjuicio que causa tal evento tiene que limitarse — según la regla de oro cuyo cumplimiento es imposible de garantizar - a la normalidad de la presión que conviene a las relaciones de trabajo afectadas, pero no puede castigar, contra todo Derecho, la generalidad de la vida en común, recayendo sobre personas y grupos que no han contraído, en la esfera del conflicto, responsabilidad alguna.

Incumbe al poder público —urgido a remover los obstáculos opuestos a la subsistencia de la igualdad y la libertad que cimentan la comunidad y su 
futuro- suplir las deficiencias que impiden el hecho del consumo de los bienes y servicios esenciales, mientras no se restaure el estado de cosas que asegure su prestación por los agentes — públicos o privados- encargados de su entrega al mercado y consiguiente oferta. Operación que constituye misión imposible ante la emocionalidad que, acompañando a las situaciones de conflicto, sabotea la racionalización de unas acciones sistemáticamente desproporcionadas.

\section{Reflexión final}

La colocación sistemática de todo o parte del Derecho Social en la vastedad dogmática e histórica del Derecho del consumo ha respondido a una concepción omnicomprensiva que resta al hecho del trabajo parte de su animación y dinamismo. Aun a riesgo de un cambio de método, parece acorde con el antropocentrismo recurrente del Derecho Social abordar la materia propuesta desde una perspectiva que, para evocar las funciones sociales del hecho del consumo, propone la siguiente consideración.

Hay una oleada de protagonistas del drama del trabajo que, ante las páginas en blanco del libro que acoja el testimonio de sus experiencias, van a escribir derecho - con los renglones torcidos de la flaqueza humana - la historia de su redención. Recordarán — como verdad de base- que su dignidad personal les pone por encima de las personas, que les oprimieron, y de las cosas que, deseando y debiendo consumirse, les fueron negadas. Estos éxitos - más o menos efímeros - no prevalecerán sobre el aprecio de una condición erguida y animosa que, frente al hecho del consumo, reclama el ejercicio de las funciones sociales que éste debe cumplir y que se esperan de sus óptimas oportunidades.

\section{Bibliografía de orientación}

ANDRIEUX, A y LIGNON, J. ¿Existe conciencia de la clase obrera?, traducción española de A. MARCos. Madrid: Ed. ZYX, 1967.

BARTocci, E. Sindacato, classe, società. Padua: Ed. CEDAM, 1975.

CACHON, L. Flexibilidad y mercado de trabajo, traducción española de $\mathrm{CH}$. Marestaing. Madrid: Ed. Centro de Publicaciones Del Ministerio DE Trabajo y Seguridad Social, 1987.

COOPER, C. M. Economía, tecnología y empleo, traducción española de F. FZ. Madrid: Ed. CEnTRO DE Publicaciones DEl Ministerio de Trabajo y SEGURIDAD Social, 1987.

DE LA VILLA, L. E. Materiales para el estudio del sindicato. Madrid: INSTITUTO DE Estudios Sociales, 1979. 
DuFTy, N. F. Cambios en las relaciones entre empresarios y trabajadores en el ámbito de la empresa, traducción española de R. SERRATACO. Madrid: Instituto de Estudios Laborales y de Seguridad Social, 1967.

Galbraith, K. L'ere de l'opulence. París: Ed. Calmann-Levy, 1961.

GorZ, A. Strategie ouvriere et neocapitalisme. París: Ed. Du SeuIL, 1964.

Halbwachs, M. Las clases sociales, traducción española de M. Aub. México-Buenos Aires: Ed. Fondo DE Cultura EconómiCA, 1964.

Lengelle, M. La consommation. París: Ed. Presses Universitaires De FRANCE, 1965.

Martín Valverde, A. et al. Derecho del Trabajo. Madrid: Ed. Tecnos, 2004.

Meynaud, J. L'evaluation et le role des besoins des biens de consommation dans les divers regimes economiques. París: Ed. C.N.R.S., 1963; Les consommateurs et le pouvoir. Lausanne: Ed. MoRnEX, 1964.

MitTelstAdT, A. et al. Mercado de trabajo y crisis económica. Madrid: Ed. Servicio de Publicaciones del Ministerio de Trabajo y Seguridad SOCIAL, 1985.

Montoya, A. Derecho del Trabajo. Madrid: Ed. TeCnos, 2005.

PACKARD, V. L'art du gaspillage. París: Ed. CALMANn-LeVy, 1962.

Quin, C. Les consommateurs. París: Ed. Du SEuIL, 1965.

SAgARDOY, J. A. Relaciones de trabajo y estructuras políticas. Madrid: Ed. Instituto de Estudios Laborales y de la Seguridad Social, 1984.

SENDON, M. et al. Sistemas de relaciones laborales y solución de conflictos colectivos en Occidente. Bilbao: Ed. CONSEJO DE RELACIONES LABORALES DE EUZKADI, 1984.

TAWNEY, R. H. La sociedad adquisitiva, traducción española de M. de FeRDINANDY. Madrid: Ed. AlianZa EdITORIAL, 1972.

Touraine, A. La coscienza operaia, traducción italiana de G. MANFredI. Milán: Ed. FRANCO ANGELI, 1975.

Ureta, J. C. y Garnica, G., Capitalismo inteligente. Madrid: Ed. Espasa CALPE, 1990.

Zorrilla, M. M. «Formación del ordenamiento extraestatal en las relaciones de trabajo», Estudios de Deusto, v. 33, pp. 230-266; «Evolución y desfiguraciones del conflicto industrial», Estudios jurídicos en memoria de JOSÉ M. ${ }^{a}$ LIDÓN. Bilbao: Ed. UnIVERSIDAD DE DeUSTO, 2002, pp. 1359-1375; «Modernidad y moralidad de la mundialización», Estudios de Deusto, v. 50/2, pp. 181-196; «Garantías precisas para el mantenimiento de los servicios esenciales de la comunidad», Revista de la Facultad de Derecho de la Universidad Complutense de Madrid, n. ${ }^{\circ} 17$ (Monográfico), pp. 226-230. 